\title{
Metalloproteinase Inhibitors: Status and Scope from Marine Organisms
}

\author{
Noel Vinay Thomas $^{1}$ and Se-Kwon Kim ${ }^{1,2}$ \\ ${ }^{1}$ Marine Biochemistry Laboratory, Department of Chemistry, Pukyong National University, Busan 608-737, Republic of Korea \\ ${ }^{2}$ Marine Bioprocess Research Center, Pukyong National University, Busan 608-737, Republic of Korea \\ Correspondence should be addressed to Se-Kwon Kim, sknkim@pknu.ac.kr
}

Received 7 August 2010; Revised 1 October 2010; Accepted 28 October 2010

Academic Editor: Sanford I. Bernstein

Copyright ( 2010 N. V. Thomas and S.-K. Kim. This is an open access article distributed under the Creative Commons Attribution License, which permits unrestricted use, distribution, and reproduction in any medium, provided the original work is properly cited.

\begin{abstract}
Marine environment has been the source of diverse life forms that produce different biologically active compounds. Marine organisms are consistently contributing with unparalleled bioactive compounds that have profound applications in nutraceuticals, cosmeceuticals, and pharmaceuticals. In this process, screening of natural products from marine organisms that could potentially inhibit the expression of metalloproteinases has gained a huge popularity, which became a hot field of research in life sciences. Metalloproteinases, especially, matrix metalloproteinases (MMPs) are a class of structurally similar enzymes that contribute to the extracellular matrix degradation and play major role in normal and pathological tissue remodeling. Imbalance in the expression of MMPs leads to severe pathological condition that could initiate cardiac, cartilage, and cancer-related diseases. Three decades of endeavor for designing potent matrix metalloproteinase inhibitory substances (MMPIs) with many not making upto final clinical trials seek new resources for devising MMPIs. Umpteen number of medicinally valuable compounds being reported from marine organisms, which encourage current researchers to screen potent MMPIs from marine organisms. In this paper, we have made an attempt to report the metalloproteinase inhibiting substances from various marine organisms.
\end{abstract}

\section{Introduction}

Metalloproteinases are a family of proteolytic enzymes generally termed as endopeptidases. This group of endopeptidases majorly consists of enzymes from metzincin family that include serralysins, astacins, adamalysins (a disintegrin and metalloproteinase domain or ADAMs), and matrixins (matrix metalloproteinases or MMPs) [1,2]. The involvement of the regulated degradation of extracellular matrix (ECM) is essential for the physiological remodeling processes like tissue repair, development, and morphogenesis. Interestingly, the remodeling process found to be uncontrolled and deleterious immunological response to repair the tissue damages, which was credited by cardio-related ailments, cancer, and arthritis [3]. MMPs are exceptionally studied and focused because of their evident role in carcinogenesis and cellular invasion by catabolising the ECM [2]. MMPs are zinc-dependant endopeptidases that degrade the ECM [4] and this remodeling of ECM facilitates several physiological processes like wound healing, bone resorption, uterine involution, and organogenesis as well as pathologic conditions including inflammatory, vascular, and autoimmune disorders, and carcinogenesis [5]. Until now, about 25 MMPS have been reported in which 24 are found in mammals [6]. It was assumed that the MMPs and their role was confined to the degradation of ECM. However, recent scientific findings from several groups have established that MMPs cleave a wide range of extracellular, bioactive substrates, and regulating the activity of such proteins, typically in a gain-of-function manner, may indeed be the predominant function of MMPs in vivo, $[6,7]$. In addition to that, MMPs play a predominant role in tumor invasion, angiogenesis, metastasis, transformation of cancer cells, signal transduction, and apoptosis [8].

Structurally, MMPs share a common domain structure, which includes propeptide domain, a catalytic metalloproteinase domain, a linker peptide often referred as hinge region and a hemopexin domain [9]. The catalytic zones 
of MMPs are compact, spherical and approximately 165 amino acid residues long with a substrate binding cleft. The extended zinc-binding motif harbors 3 zinc-binding histidines and a glutamate that preferentially serves as acid/base during catalytic reactions. MMP molecules possess three $\alpha$-helices and a five-stranded $\beta$ sheet as well as at least two calcium sites and a second zinc site which renders structural functions for these molecules [10]. The substrate specificity of MMPs is determined by a hydrophobic pocket called $S 1^{\prime}$ pocket which is found at the catalytic domain. Hence the $\mathrm{S1}^{\prime}$ pocket that determines the substrate specificity for MMPs becomes an inevitable source to devise MMP inhibitors [10].

Generally, intercellular regulation and cell matrix adhesion is regulated in a controlled manner, however, predominant human-related cancers are found with the dysregulation of these two phenomena. These pathological changes are due to the superior expressions of MMPs, the proteolytic enzymes [11]. The regulation of MMPs is controlled by endogenous inhibitors like tissue inhibitors of metalloproteinase (TIMPs), $\alpha_{2}$-macroglobin, heparin, and the reversion-inducing cysteine-rich protein with kazal motifs. TIMPs are naturally occurring inhibitors of MMPs and they form noncovalent $1: 1$ stoichiometric complexes with MMPs and prevent the proteolytic degradation [12]. Although the TIMPs have inhibitory activities on MMPs, they differ in many aspects like solubility, interaction with proenzymes (Pro-MMPs) and also regulation of expression [13]. Interactions and regulation of specific MMPs and other proteases by specific members of TIMP family are thoroughly discussed elsewhere [14-17].

MMPs association with various pathological responses has initiated an outstanding scientific preference to design the most potent MMPIs in the last 20 years. Many potential MMPIs have been formulated, however the challenging concept was that these inhibitors displayed poor selectivity towards MMP members and also the significance of blocking unrelated zinc proteases became an obstacle [18]. The strategies of designing MMPIs were based on the chelating of $\mathrm{Zn}^{2+}$ that induces inhibition of MMPs. Chelating groups like hydroxyl amine, carboxyl, thiol and so forth, were predominantly used. Commercially successful MMPIs like Batimastat (BB-94), Marimastat (BB-516) are known to have strong $\mathrm{Zn}^{2+}$ chelating group, hydroxamate. The poor selectivity, improper metabolism, low oral bioavailability, poor solubility, side effects like musculoskeletal pain and inflammation, complications and the risk of increased drug toxicity have strongly eliminated the first generation MMPIs from clinical trials $[9,19,20]$.

As the above discussed scientific observations clearly bring front the point of reported MMPIs' failure in clinical trials, the need of designing novel MMPIs specific to MMPs is being the major concern. The new generation MMPI research suggests that the thorough study on $\mathrm{S1}^{\prime}$ pocket of MMPs could increase the selectivity of MMPs and also is thought to prove beneficial in reducing the risk of other MMP-related diseases [21, 22]. According to Chen et al., the MMPIs can be broadly divided into 4 classes: the natural MMPIs secreted by tissues; synthetic MMPIs; MMPIs screened from natural products; the MMPIs screened from the phage display random peptide library and antibody library. However, as the synthetic MMPIs indeed have few shortcomings at clinical usage, MMPIs derived from natural sources are being considered more for current time research. Until now, umpteen number of research groups have worked to achieve MMPIs from terrestrial sources and reported several outstanding natural MMPIs [23, 24]. For ages, it has been believed and proved that oceans harbor a variety of life forms ranging from microorganisms to vertebrates, which in turn provide mankind with several benefits biologically and medicinally. This feature of wide diversity in marine life forms has been identified as chief source for unique biologically active compounds that exhibit tremendous potential for pharmaceutical applications [25]. As these oceanic organisms are not completely exploited or studied well for their medicinal values, this field of research has gained lots of attention these days. This paper narrates a descriptive past research work carried out on MMPIs derived from marine organisms and in addition, the specific areas of metalloproteinase research have been outlined in a perspective manner.

\section{Marine Animals}

Fish from marine sources are abundant in omega-3 longchain polyunsaturated fatty acids ( $\omega 3$ LC-PUFAs) like eicosapentaenoic acid (EPA) and docosahexaenoic acid (DHA). Judé et al. have reported and compared some proposed mechanisms for the involvement of omega-3 LC-PUFAs in both cardiac and breast cancer protection [26]. Simple products like dietary oils from fish have been reported to exert beneficial properties in lowering the expressions of proMMP-2 and proMMP-9, that makes the dietary fish oil, a potential MMP inhibiting substance and can reduce the risk of inflammatory joint diseases [27]. Another research group has reported that oleic acid (OA), docosahexaenoic acid (DHA), and eicosapentaenoic acid (EPA) have significantly inhibited the lung metastasis by colon-carcinoma-26 cells by downregulating the activities of MMP-2 and -9 [28]. Diets supplemented with DHA reduce the metalloproteinase production in uterus, placenta, and liver tissues of rat. These findings suggest that competitive incorporation of $\omega 3$ LCPUFAs and arachidonic acid into membrane phospholipids would consequently affect the MMP activities by bringing a change in the production of prostaglandin PGE2 [29]. A 21-kDa proteinase inhibitor from Gadus morhua (Atlantic cod) that shares similar properties to that of human TIMP2 was investigated by Lødemel et al., whose studies revealed that this inhibitor has suppressed the gelatinolytic activity obtained from a human macrophage cell medium rich in MMP-9 [30], recommending it as a potent MMP inhibiting marine substance. Similar to this, shark cartilage is a source of antiangiogenic and antitumor compounds [31]. A novel antiangiogenic and antiinflammatory agent, AE 941 from shark cartilage has been studied by Dupont et al., who reported the effectiveness of this substance in treating psoriasis [32]. Compounds extracted from shark cartilage such as Neovastat, AE-941, U-995 have been 
checked for their antiangiogenic and antimetastatic effects. Neovastat has been found to inhibit MMP-2 and partially MMP-1, $-7,-9$ and -13 . Western blot analysis confirms the presence of TIMP-like proteins within AE-941 that might be responsible in inhibiting the MMPs [33]. Our previous studies of potent ACE inhibitory peptide from tuna frame protein (PTFP) hydrolysate has shown antihypertensive effect in spontaneously hypertensive rats (SHRs) [34]. Earlier scientific investigations proved that ACE and MMPs are closely related to coronary diseases and the ACE inhibitors not only target ACE but also MMPs. Yamamoto and Takai have postulated that molecular interaction between MMP-9 active sites and ACE inhibitors could brighten up the chances for MMP inhibitors for cardioprotection [35].

Marine cephalopods and their metabolites have been reported to have many applications in the field of medicine. SIP-SII is the sulfated ink polysaccharide (SIP) isolated from cuttlefish; Sepiella maindroni has been evaluated for its ability to inhibit the invasion and migration of SKOV3 and ECV304 cells via inhibition of MMP-2 proteolytic activity [36]. The backbone of SIP-SII is composed of fucose, $\mathrm{N}$-acetylgalactosamine, mannose, and a single branch of glucuronic acid at the C-3 position of mannose with 34.7\% of sulfated group [46]. Sulphated polysaccharides are known for their inhibition potential of MMPs [47-50] and especially the metastasis in cancer is strongly inhibited by the $O$ Sulfated polysaccharide [51]. Thus SIP-SII can be considered as a substance that can inhibit MMP-2 expression. According to Chen et al., SIP-named TBA-1 from the ink of Ommastrephes bartrami potentially inhibits the cell invasion and migration in HepG2, which proved once again that SIPs are becoming the best candidates as metalloproteinase inhibiting substances [52].

Marine sponges by being the most diversified faunal communities of seas, have contributed in discovering potential MMP inhibiting compounds. Ageladine A (1), a fluorescent alkaloid isolated from marine sponge Agelas nakamurai has the capability of inhibiting not only MMP2 but also MMP-1, $-8,-9,-12$, and -13 . This compound also inhibited the migration of bovine aortic endothelial (BAE) cells significantly. However, the mechanism of inhibiting the MMPs is not clear because the research results say that Ageladine A (1) did not chelate the $\mathrm{Zn}^{+2}$ and moreover the mode of inhibition is presumed to be other than the competitive inhibition [37]. Another study on Ancorinosides B, C, D isolated from the marine sponge Penares sollasi Thiele has shown an inhibitory effect on membrane type 1 matrix metalloproteinase (MT1-MMP) with $\mathrm{IC}_{50}$ values of $180-500 \mu \mathrm{g} / \mathrm{mL}$. These ancorinosides contain two carboxylic acids and a tetramic acid group and it is presumed that the latter plays an effective role in the inhibition of MMPs [38]. An antibacterial brominated compound produced by certain sponges named (+)-aeroplysinin-1 exhibited a clear inhibitory effect on the migration capabilities of endothelial cells. The inhibitory effects on MMP-2 and urokinase are revealed by the zymographic studies suggesting aeroplysinin1 as a promising drug for angiogenesis-related pathologies [53]. According to the review by R. G. Kerr and S. S. Kerr debromohymenialdisine and its related compounds from a sponge genus Hymeniacidon were reported to inhibit the calf joint cartilage degradation by downregulating the metalloproteinases [54]. Poecillastra sp. and Jaspis sp. are known to harbor Psammaplin A (PsA) a natural bromotyrosine [55], where PsA is reported to have strong antiproliferative, antiangiogenic properties, which undoubtedly suggest PsA as a potential antiangiogenic agents [56].

Recently, a novel oligopeptide SHP-1, rich in acidic amino acids, aspartic acid (Asp) and glutamic acid (Glu) was isolated from sea horse Hippocampus Syngnathidae [39]. The sequence of the isolated oligopeptide is LEDPFDKDDWDNWKS, which was investigated for its ability to inhibit the expression of MMP-1, -3 and -13 thus preventing the cartilage damage in human chondrocytic (SW-1353) and osteoblastic (MG-63) cells. These results strongly support that metalloproteinases possess binding sites that are open for Asp and Glu and also Asp helps in rejuvenation of cell formation, cellular activity, and metabolism [57]. The cartilage preventive property of SPH-1 could be possible because of its down regulatory effect on the expression of MMP-1 and -13 which are thought to play a key role in the destruction of cartilage [58]. The same research group has reported pronase E-derived hydrolysate peptide of $1821 \mathrm{Da}$ from a sea horse, Hippocampus kuda Bleeler. This peptide has been checked for its induction of differentiation of osteoblastic MG-63 and chondrocytic SW-1353 cells by measuring ALP activity, mineralization, and collagen synthesis. Interestingly, their results indicate that the respective peptide has considerably inhibited the MMP- $1,-3$ and -13 by picking the mechanism of reducing p38 kinase/NF- $\kappa$ B in MG-63 cells and MAPKs/NF- $\kappa$ B in SW-1353 cells [59]. These results clearly indicate that marine organisms are an excellent choice to devise MMPIs. Analysis of a gene for naturally occurring TIMP from pacific oyster Crassostrea gigas named cg-TIMP, the first tissue inhibitor of metalloproteinase from mollusks, revealed that it is closely related to vertebrate TIMP family and is effectively involved in wound healing as well as in defense mechanisms [60]. Exploitation of this feature by the use of gene technology could result in potential natural MMPI mimics that could be compatible for humans.

Mucopolysaccharide called chitin from crustacean shells has been known for its vast application in nutraceuticals and as well as pharmaceuticals. Kong et al. synthesized water-soluble derivatives of chitin and chitosan, carboxymethyl-chitosan (CM-chitosan) and carboxymethylchitin (CM-chitin) by means of carboxymethylation reaction and evaluated their effect on the expressions of MMPs. As per their investigations, CM-chitin exhibited a higher MMP inhibitory, (MMP-2 and MMP-9) effect than CMchitosan through transcriptional downregulations of activator protein-1 (AP-1) and nuclear factor $\kappa \mathrm{B}(\mathrm{NF}-\kappa \mathrm{B})$, thus reporting $\mathrm{CM}$-chitin and $\mathrm{CM}$-chitosan as strong antioxidants and potent MMP inhibiting natural polymers [61]. Chitooligosaccharides (COS) ranging from $3-5 \mathrm{kDa}$ has been reported to have a strong inhibitory effect on MMP2 by decreasing the gene expression and transcriptional activity of MMP-2. Moreover COS of the same molecular weight represses the gene expression of c-fos, a part of AP-1 transcription factor suggesting that they can combat 
TABLE 1: List of important substances from marine organisms that inhibit metalloproteinases.

Substance Structure References

Sulfated ink polysaccharide (SIP)

$\begin{array}{cc} & \text { Structu } \\ \longrightarrow 4-\beta \text {-L-Fucp }(1 \rightarrow 4)-\beta \text {-L-Fucp }(1 \longrightarrow 4)-\alpha \text {-D-GalpNAc- } & \text { D }\end{array}$

$\mathrm{B}$

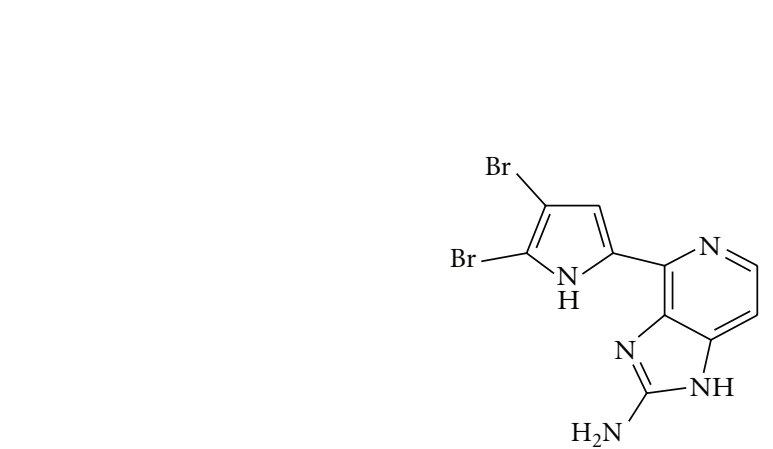

3
$\uparrow$

$-(1 \longrightarrow 4)-\alpha-\mathrm{D}-\mathrm{Gal} p \mathrm{NAc}-(1 \longrightarrow$

A

Ageladine A (1)

Ancorinoside (B)

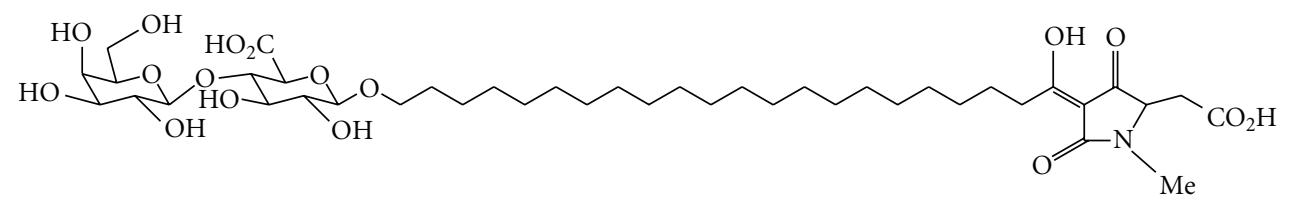

SHP-1

LEDPFDKDDWDNWKS

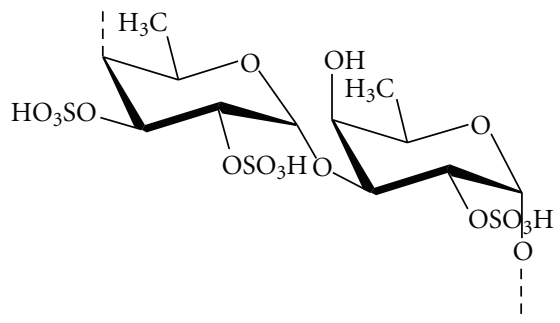

Fucoidan<smiles>Oc1cccc(O)c1</smiles>

Eckol<smiles>Oc1cc(O)c2c(c1)Oc1c(O)cc(O)c(Cl)c1O2</smiles>

Dieckol<smiles>Oc1cc(O)cc(Oc2c(O)cc(O)c3c2Oc2cc(Oc4c(O)cc(Oc5c(O)cc(O)c6c5Oc5c(O)cc(O)cc5O6)cc4O)cc(O)c2O3)c1</smiles> 
TABle 1: Continued.

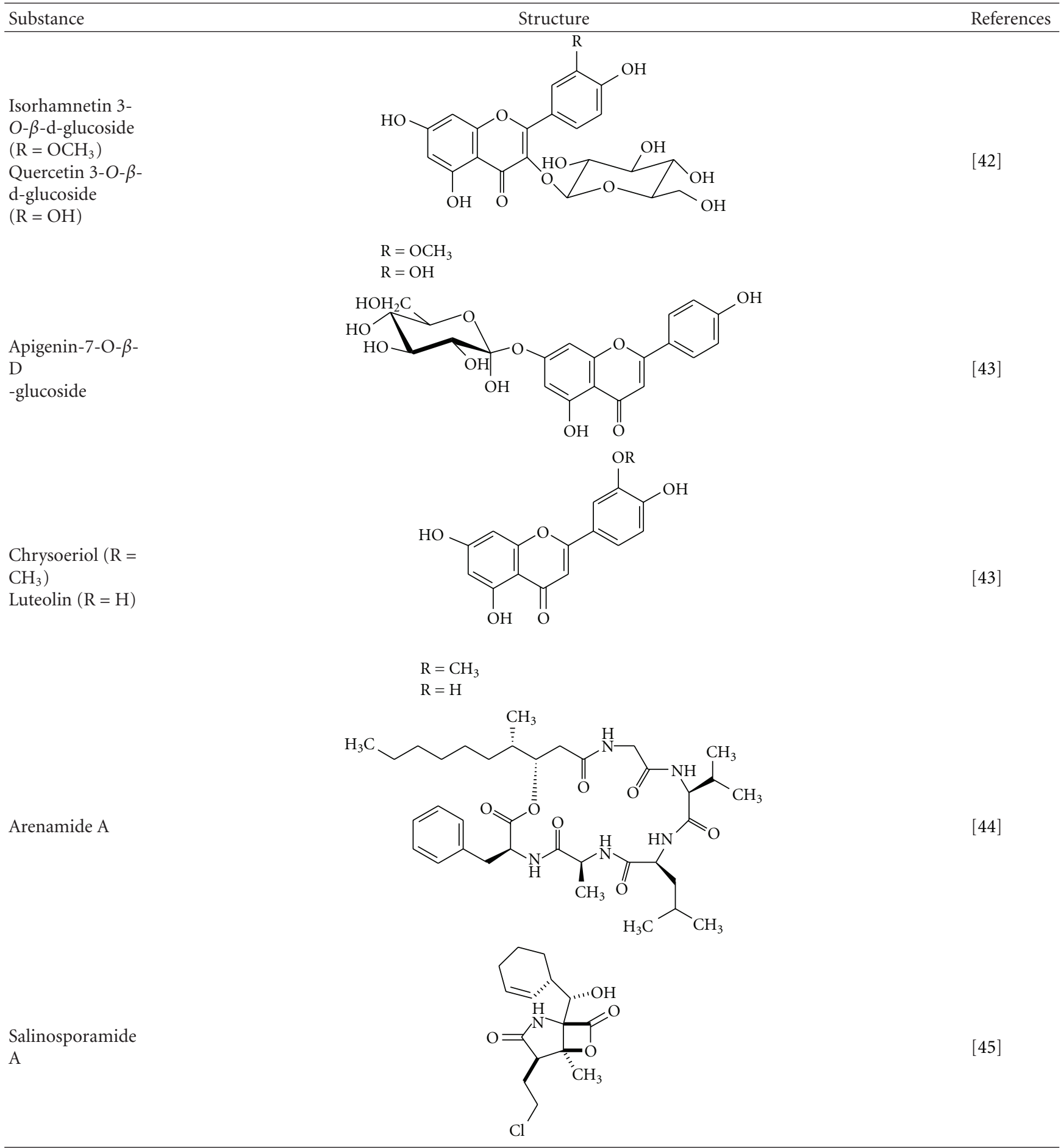

metalloproteinase-related pathological processes like metastasis and wrinkle formation [62]. Rajapakse et al. have reported that carboxylated chitooligosaccharides (CCOS) downregulate the MMP-9 expression in human fibrosarcoma (HT-1080) cells. In addition, CCOS is able to reduce the expression of MMP-9 by downregulating the MMP-9 at transcription level, mediated via the inhibition of AP-1 [63].
Brito et al. have reported about antiinflammatory properties of a heparin-like compound from the shrimp Litopenaeus vannamei. Their observations postulated that this compound has not only reduced the influx of inflammatory cells to injury site but also has an outstanding capability of inhibiting MMP-9 activity to $90 \%$. The structural feature of this heparin-like protein from shrimp which has high 
content of glucuronic acid and disulfated disaccharide units renders the anticoagulant and hemorrhagic activities, which clearly recommends this heparin like substance as better antiinflammatory drug [64]. Heparinoid from shrimp has been reported to have potent antiangiogenic and antiinflammatory activities with insignificant anticoagulant or hemorrhagic actions, thus making shrimp heparinoid as a potent drug to treat neovascular age-related macular degeneration (AMD) and other angioproliferative diseases [65].

\section{Marine Plants}

Metabolites from marine plants have been reported to have outstanding biological activities. A highly effective anticoagulant and antiproliferative agent called, sulfated polysaccharide has been reported from a brown alga Ecklonia cava, which exhibited a promising antiproliferative effect on human promyelocytic leukemia (HL-60) and human leukemic monocyte lymphoma (U-937) cells at an $\mathrm{IC}_{50}$ value of $43.9 \mu \mathrm{g} / \mathrm{mL}$ [66]. Fucoidan extracts from seaweed Cladosiphon novae-caledoniae Kylin (Mozuku) have reduced the cellular invasiveness in human fibrosarcoma HT1080 cells by suppressing the activity of MMP-2 and MMP-9. Further, it has been reported that these fucoidan extracts suppressed the expression and secretion of an angiogenesis factor, vascular endothelial growth factor (VEGF) thereby reporting the inhibitory effects on invasion and angiogenesis of tumor cells [67]. Fucoidan from Costaria costata of the order Laminariales, has an outstanding inhibitory effect of minimizing UV-B-induced MMP-1 expression by $41.8 \%$ at $0.01 \mu \mathrm{g} / \mathrm{mL}, 57.7 \%$ at $0.1 \mu \mathrm{g} / \mathrm{mL}$, and $70 \%$ at $1 \mu \mathrm{g} / \mathrm{mL}$, compared to UVB irradiation alone $(P<.05)$ in immortalized human keratinocyte (HaCaT) cells [40].

Methanolic extracts from marine red alga Corallina pilulifera (CPM) have potentially reduced the expression of UV-induced MMP-2 and MMP-9 in human dermal fibroblast (HDF) cell suggesting CPM as an effective antiphoto ageing agent [68]. In spirit of designing new antiphotoaging agents, Joe et al. reported that extracts from 3 species of Alariaceae, Eisenia bicyclis, Ecklonia cava, and Ecklonia stolonifera, have strongly reduced MMP-1 expression via inhibiting both NF-kappaB and AP-1 reporter. Moreover attenuation of MMP-1 expression was evident by treatment with eckol or dieckol, which were purely isolated from E. stolonifera in human dermal fibroblasts [41]. The phlorotannins eckol and dieckol were first isolated from Ecklonia species possess oligomeric polyphenol of phloroglucinol unit [69]. Various biological activities including free radical scavenging activity of phlorotannins from Ecklonia species have been reported earlier [70]. Dieckol from marine brown alga, E. cava has been reported to suppress LPS-induced production of nitric oxide (NO) and prostaglandin $\mathrm{E}_{2}\left(\mathrm{PGE}_{2}\right)$ and expression of inducible nitric oxide synthase (iNOS) and cyclooxygenase-2 (COX-2) in murine BV2 microglia, thus establishing dieckol as a potent antiinflammatory and neuroprotective agent [71].

Salicornia herbacea, a halophyte that grows on salt marshes and muddy seashores along the western coast of
Korea. Kong et al. have reported that flavonoid glycosides, isorhamnetin 3-O- $\beta$-d-glucoside, and quercetin 3-O$\beta$-d-glucoside isolated from this plant have inhibited the expression of MMP-2 and MMP-9 and elevated the TIMP1 expression in human fibrosarcoma (HT1080) cells, which was confirmed by western blot. The biological activity of these flavonoids is believed to be contributed by the presence of phenolic hydroxyl groups [72]. Moreover, the downregulation of MMP-9 and MMP-2 by these flavonoids is due to the interference with the transcription factor AP1 there by suggesting these flavonoid glycosides as potent natural chemopreventive agents for cancer [42]. Mook-Jung et al. have worked on the constituents of two Rhodiola plants, Rhodiola sacra S. H. Fu and Rhodiola sachalinensis A. Bor, reporting that out of the 58 compounds tested, six had considerable protective effects against beta-amyloid-induced death of B103 neuronal cells in vitro [73]. The extracts from sea grass Zostera marina L., apigenin-7-O- $\beta$-D-glucoside (1), chrysoeriol (2), and luteolin (3) can scavenge reactive oxygen species. Especially, luteolin has remarkable inhibitory activity on MMP-1 for upto $44 \%$ at $4.0 \mathrm{uM}$. The research results suggest that luteolin (3) inhibited the MMP-1 expression by suppressing the IL-6 expression by $30 \%$ at $4.0 \mu \mathrm{M}$ [43]. It suggests that these extracts can combat photoaging induced by UV rays.

In the exploration of marine natural antioxidants, two bioactive isolates floridoside and d-isofloridoside from marine edible red alga Laurencia undulata have been studied by $\mathrm{Li}$ et al. and are reported for their profound effect on scavenging free radicals and inhibiting the metalloproteinases MMP-2 and -9. The structure-activity relationships (SARs) studies suggest that the effective antioxidant activity of these floridosides is rendered by the galactose group and glycerol residue which can donate hydrogen ion and in turn excited hydroxyl groups can attract electrons easily [74]. Phlorotannins from brown alga E. cava have been reported to have inhibitory activity on MMP-2 and MMP9 signifying the role of phlorotannins as potential and safe marine derived MMPIs [75]. These findings clearly suggest that purified extracts from E. cava inhibit MMP activity at a lower concentration and reduce the incidence of metastasis and skin wrinkle in vivo model.

\section{Marine Microorganisms}

Around $70 \%-80 \%$ of marine environment is dominated by various kinds of microorganisms that possess biologically active compounds. Calcium spirulan (Ca-SP) isolated from Spirulina platensis, a marine unicellular alga was able to reduce the melanoma (as studied in B16-BL6 cells), carcinoma (evidenced in colon 26-M3.1 cells), and fibrosarcoma (evidenced in HT-1080 cells). These findings confirm the possible role of $\mathrm{Ca}-\mathrm{Sp}$ in interfering with the MMPs and disabling the tumor invasion [76]. Yang et al. reported that polysaccharide extract from S. platensis (PSP) inhibits corneal neovascularization (CNV) caused by alkali burns. Their findings clearly show that application of PSP has reduced several parameters related to $\mathrm{CNV}$ and/or 
inflammation including the downregulation of MMP-2 and MMP-9 [77]. Species of Chlorella are known for their vast application in nutraceuticals. However, antioxidants extracted from Chlorella vulgaris by a special supercritical carbon dioxide extraction $\left(\mathrm{SC}-\mathrm{CO}_{2}\right)$ technology has proven advantage in inhibiting MMP-mediated cancer proliferation and progression via the suppression of cellular invasion and metastasis [78].

Asolkar et al. reported arenamides A-C (1-3), from Salinispora arenicola, a marine bacterial strain and the effect of arenamides $\mathrm{A}$ and $\mathrm{B}$ on $\mathrm{NF} \kappa \mathrm{B}$ activity in stably transfected to 293/NFkB-Luc human embryonic kidney cells, which revealed an outstanding blockage of TNF-induced activation. As expression of MMP-9 gene is an outcome of $\mathrm{NF} \kappa \mathrm{B}$ activity, further sophisticated studies could make the arenamides potential MMP inhibiting compounds [44]. Marine bacterium Salinispora tropica renders salinosporamide A (also called NPI-0052), which was recently identified by Ahn et al. They have monitored the salinosporamide A's ability to potentiate the apoptosis induced by tumor necrosis factor- $\alpha$ (TNF- $\alpha$ ), bortezomib, and thalidomide, and this mechanism was correlated with the downregulation of cancer-related gene products including MMP-9 that plays a role in tumor invasion. Thus by suppressing the NF- $\kappa \mathrm{B}$ pathway salinosporamide proved to be a promising MMP inhibiting molecule [45].

\section{Conclusions}

In recent years, oceans' flora and fauna have been studied extensively for their biochemical responses to evade potential threats they encounter in marine locales. This has led to the idea of exploiting those biochemicals, in other words natural products to be used as potential inputs in medicinal applications that would prove to be beneficial in uplifting human health. The recent scientific investigations unleashing the prominence of metalloproteinases in several human-related ailments and the drawbacks of the currently available synthetic antimetalloproteinases encourages the present day researchers to explore natural resources for more devising reliable and specific MMPIs. Synthetic MMPIs have few shortcomings like nonspecific selectivity, improper metabolization that often leads to undesirable side effects, poor bioavailability and so forth. These have been the key reasons to put most of the synthetic MMPIs out of clinical trials. While on the other side, MMPIs from marine organisms like fish, mollusks, cephalopods, red algae, brown algae, few marine bacteria have reportedly given much promising results (Table 1). However, screening of MMPIs from marine organisms that specifically bind to the $\mathrm{S1}^{\prime}$ pocket of metalloproteinases and the substances which can show competence to bind with the active site of metalloproteinases is much challenging. Considering the species and technologies explored, it can be said that exploration has just confined to the tip of an ice berg. With the current cutting edge scientific approaches, more marine organisms and their products can be explored and studied for coming up with the apt marine natural MMPIs.

\section{Acknowledgments}

This research was supported by a grant from Marine Bioprocess Research Center of the Marine Bio 21 center funded by the Ministry of Land, Transport and Maritime, Republic of Korea. The authors are thankful to Mr. Jayachandran Venkatesan for redrawing the chemical structures in Table 1. Samples are available from the authors.

\section{References}

[1] J. Huxley-Jones, T.-K. Clarke, C. Beck, G. Toubaris, D. L. Robertson, and R. P. Boot-Handford, "The evolution of the vertebrate metzincins; insights from Ciona intestinalis and Danio rerio," BMC Evolutionary Biology, vol. 7, article 63, 2007.

[2] S. E. Gill and W. C. Parks, "Metalloproteinases and their inhibitors: regulators of wound healing," International Journal of Biochemistry and Cell Biology, vol. 40, no. 6-7, pp. 13341347, 2008.

[3] G. Murphy and H. Nagase, "Progress in matrix metalloproteinase research," Molecular Aspects of Medicine, vol. 29, no. 5, pp. 290-308, 2008.

[4] M.-H. Lee and G. Murphy, "Matrix metalloproteinases at a glance," Journal of Cell Science, vol. 117, no. 18, pp. 4015-4016, 2004.

[5] M. Egeblad and Z. Werb, "New functions for the matrix metalloproteinases in cancer progression," Nature Reviews Cancer, vol. 2, no. 3, pp. 161-174, 2002.

[6] W. C. Parks, C. L. Wilson, and Y. S. López-Boado, "Matrix metalloproteinases as modulators of inflammation and innate immunity," Nature Reviews Immunology, vol. 4, no. 8, pp. 617629, 2004.

[7] J. D. Mott and Z. Werb, "Regulation of matrix biology by matrix metalloproteinases," Current Opinion in Cell Biology, vol. 16, no. 5, pp. 558-564, 2004.

[8] C. M. Overall and C. López-Otín, "Strategies for MMP inhibition in cancer: innovations for the post-trial era," Nature Reviews Cancer, vol. 2, no. 9, pp. 657-672, 2002.

[9] C. Zhang and S.-K. Kim, "Matrix metalloproteinase inhibitors (MMPIs) from marine natural products: the current situation and future prospects," Marine Drugs, vol. 7, no. 2, pp. 71-84, 2009.

[10] C. Tallant, A. Marrero, and F. X. Gomis-Rüth, "Matrix metalloproteinases: fold and function of their catalytic domains," Biochimica et Biophysica Acta, vol. 1803, no. 1, pp. 20-28, 2010.

[11] D. Bourboulia and W. G. Stetler-Stevenson, "Matrix metalloproteinases (MMPs) and tissue inhibitors of metalloproteinases (TIMPs): positive and negative regulators in tumor cell adhesion," Seminars in Cancer Biology, vol. 20, no. 3, pp. 161-168, 2010.

[12] D. E. Gomez, D. F. Alonso, H. Yoshiji, and U. P. Thorgeirsson, "Tissue inhibitors of metalloproteinases: structure, regulation and biological functions," European Journal of Cell Biology, vol. 74, no. 2, pp. 111-122, 1997.

[13] E. Lambert, E. Dassé, B. Haye, and E. Petitfrère, "TIMPs as multifacial proteins," Critical Reviews in Oncology/Hematology, vol. 49, no. 3, pp. 187-198, 2004.

[14] S. M. Wilhelm, I. E. Collier, B. L. Marmer, A. Z. Eisen, G. A. Grant, and G. I. Goldberg, "SV40-transformed human lung fibroblasts secrete a $92-\mathrm{kDa}$ type IV collagenase which is identical to that secreted by normal human macrophages," 
Journal of Biological Chemistry, vol. 264, no. 29, pp. 1721317221, 1989.

[15] R. V. Ward, R. M. Hembry, J. J. Reynolds, and G. Murphy, “The purification of tissue inhibitor of metalloproteinases- 2 from its $72 \mathrm{kDa}$ progelatinase complex. Demonstration of the biochemical similarities of tissue inhibitor of metalloproteinases2 and tissue inhibitor of metalloproteinases-1," Biochemical Journal, vol. 278, part 1, pp. 179-187, 1991.

[16] A. Amour, C. G. Knight, A. Webster et al., "The in vitro activity of ADAM-10 is inhibited by TIMP-1 and TIMP-3," FEBS Letters, vol. 473, no. 3, pp. 275-279, 2000.

[17] R. A. Williamson, M. D. Carr, T. A. Frenkiel, J. Feeney, and R. B. Freedman, "Mapping the binding site for matrix metalloproteinase on the N-terminal domain of the tissue inhibitor of metalloproteinases-2 by NMR chemical shift perturbation," Biochemistry, vol. 36, no. 45, pp. 13882-13889, 1997.

[18] A. Yiotakis and V. Dive, "Third-generation MMP inhibitors: recent advances in the development of highly selective inhibitors," in The Cancer Degradome, pp. 811-825, Springer, Amsterdam, The Netherlands, 2008.

[19] L. M. Coussens, B. Fingleton, and L. M. Matrisian, "Matrix metalloproteinase inhibitors and cancer: trials and tribulations," Science, vol. 295, no. 5564, pp. 2387-2392, 2002.

[20] M. Pavlaki and S. Zucker, "Matrix metalloproteinase inhibitors (MMPIs): the beginning of phase I or the termination of phase III clinical trials," Cancer and Metastasis Reviews, vol. 22, no. 2-3, pp. 177-203, 2003.

[21] C. M. Overall and C. P. Blobel, "In search of partners: linking extracellular proteases to substrates," Nature Reviews Molecular Cell Biology, vol. 8, no. 3, pp. 245-257, 2007.

[22] A.-C. Dublanchet, P. Ducrot, C. Andrianjara et al., "Structurebased design and synthesis of novel non-zinc chelating MMP12 inhibitors," Bioorganic and Medicinal Chemistry Letters, vol. 15, no. 16, pp. 3787-3790, 2005.

[23] U.-K. Seo, Y.-J. Lee, J.-K. Kim et al., "Large-scale and effective screening of Korean medicinal plants for inhibitory activity on matrix metalloproteinase-9," Journal of Ethnopharmacology, vol. 97, no. 1, pp. 101-106, 2005.

[24] K.-T. Ha, J.-K. Kim, S.-K. Kang et al., "Inhibitory effect of Sihoga-Yonggol-Moryo-Tang on matrix metalloproteinase-2 and -9 activities and invasiveness potential of hepatocellular carcinoma," Pharmacological Research, vol. 50, no. 3, pp. 279285, 2004.

[25] R. Jain, "Marine life: new hope for cancer drugs," Indian Journal of Cancer, vol. 46, no. 3, pp. 243-244, 2009.

[26] S. Judé, S. Roger, E. Martel et al., "Dietary long-chain omega-3 fatty acids of marine origin: a comparison of their protective effects on coronary heart disease and breast cancers," Progress in Biophysics and Molecular Biology, vol. 90, no. 1-3, pp. 299325, 2006.

[27] R. A. Hansen, M. A. Harris, G. E. Pluhar et al., "Fish oil decreases matrix metalloproteinases in knee synovia of dogs with inflammatory joint disease," Journal of Nutritional Biochemistry, vol. 19, no. 2, pp. 101-108, 2008.

[28] I. Suzuki, M. Iigo, C. Ishikawa et al., "Inhibitory effects of oleic and docosahexaenoic acids on lung metastasis by colon-carcinoma-26 cells are associated with reduced matrix metalloproteinase-2 and -9 activities," International Journal of Cancer, vol. 73, no. 4, pp. 607-612, 1997.

[29] M. A. Harris, R. A. Hansen, P. Vidsudhiphan et al., "Effects of conjugated linoleic acids and docosahexaenoic acid on rat liver and reproductive tissue fatty acids, prostaglandins and matrix metalloproteinase production," Prostaglandins Leukotrienes and Essential Fatty Acids, vol. 65, no. 1, pp. 23-29, 2001.

[30] J. B. Lødemel, W. Egge-Jacobsen, and R. L. Olsen, "Detection of TIMP-2-like protein in Atlantic cod (Gadus morhua) muscle using two-dimensional real-time reverse zymography," Comparative Biochemistry and Physiology Part B, vol. 139, no. 2, pp. 253-259, 2004.

[31] R. P. González, A. Leyva, and M. O. Moraes, "Shark cartilage as source of antiangiogenic compounds: from basic to clinical research," Biological and Pharmaceutical Bulletin, vol. 24, no. 10, pp. 1097-1101, 2001.

[32] É. Dupont, P. E. Savard, C. Jourdain et al., "Antiangiogenic properties of a novel shark cartilage extract: potential role in the treatment of psoriasis," Journal of Cutaneous Medicine and Surgery, vol. 2, no. 3, pp. 146-152, 1998.

[33] R. M. Bukowski, "AE-941, a multifunctional antiangiogenic compound: trials in renal cell carcinoma," Expert Opinion on Investigational Drugs, vol. 12, no. 8, pp. 1403-1411, 2003.

[34] S.-H. Lee, Z.-J. Qian, and S.-K. Kim, "A novel angiotensin I converting enzyme inhibitory peptide from tuna frame protein hydrolysate and its antihypertensive effect in spontaneously hypertensive rats," Food Chemistry, vol. 118, no. 1, pp. 96-102, 2010.

[35] D. Yamamoto and S. Takai, "Pharmacological implications of MMP-9 inhibition by ACE inhibitors," Current Medicinal Chemistry, vol. 16, no. 11, pp. 1349-1354, 2009.

[36] S. Wang, Y. Cheng, F. Wang et al., "Inhibition activity of sulfated polysaccharide of Sepiella maindroni ink on matrix metalloproteinase (MMP)-2," Biomedicine and Pharmacotherapy, vol. 62, no. 5, pp. 297-302, 2008.

[37] M. Fujita, Y. Nakao, S. Matsunaga et al., "Ageladine A: an antiangiogenic matrixmetalloproteinase inhibitor from the marine sponge Agelas nakamurai," Journal of the American Chemical Society, vol. 125, no. 51, pp. 15700-15701, 2003.

[38] M. Fujita, Y. Nakao, S. Matsunaga et al., "Ancorinosides B$\mathrm{D}$, inhibitors of membrane type 1 matrix metalloproteinase (MT1-MMP), from the marine sponge Penares sollasi Thiele," Tetrahedron, vol. 57, no. 7, pp. 1229-1234, 2001.

[39] B. Ryu, Z.-J. Qian, and S.-K. Kim, "SHP-1, a novel peptide isolated from seahorse inhibits collagen release through the suppression of collagenases 1 and 3 , nitric oxide products regulated by NF- $\kappa \mathrm{B} / \mathrm{p} 38$ kinase," Peptides, vol. 31, no. 1, pp. 79-87, 2010.

[40] H. J. Moon, K. S. Park, M. J. Ku et al., "Effect of Costaria costata fucoidan on expression of matrix metalloproteinase1 promoter, mRNA, and protein," Journal of Natural Products, vol. 72, no. 10, pp. 1731-1734, 2009.

[41] M.-J. Joe, S.-N. Kim, H.-Y. Choi et al., "The inhibitory effects of eckol and dieckol from Ecklonia stolonifera on the expression of matrix metalloproteinase-1 in human dermal fibroblasts," Biological and Pharmaceutical Bulletin, vol. 29, no. 8, pp. 1735-1739, 2006.

[42] C.-S. Kong, Y. A. Kim, M.-M. Kim et al., "Flavonoid glycosides isolated from Salicornia herbacea inhibit matrix metalloproteinase in HT1080 cells," Toxicology in Vitro, vol. 22, no. 7, pp. 1742-1748, 2008.

[43] J. Kim, Y. Cho, S. Park et al., "Antioxidants and inhibitor of matrix metalloproteinase-1 expression from leaves of Zostera marina L," Archives of Pharmacal Research, vol. 27, no. 2, pp. 177-183, 2004.

[44] R. N. Asolkar, K. C. Freel, P. R. Jensen et al., "Arenamides A$\mathrm{C}$, cytotoxic $\mathrm{NF} \kappa \mathrm{B}$ inhibitors from the marine actinomycete salinispora arenicola," Journal of Natural Products, vol. 72, no. 3, pp. 396-402, 2009. 
[45] K. S. Ahn, G. Sethi, T.-H. Chao et al., "Salinosporamide a (NPI-0052) potentiates apoptosis, suppresses osteoclastogenesis, and inhibits invasion through down-modulation of NF$\kappa \mathrm{B}$-regulated gene products," Blood, vol. 110, no. 7, pp. 2286 2295, 2007.

[46] C. Liu, X. Li, Y. Li, Y. Feng, S. Zhou, and F. Wang, "Structural characterisation and antimutagenic activity of a novel polysaccharide isolated from Sepiella maindroni ink," Food Chemistry, vol. 110, no. 4, pp. 807-813, 2008.

[47] S. Koyanagi, N. Tanigawa, H. Nakagawa, S. Soeda, and H. Shimeno, "Oversulfation of fucoidan enhances its antiangiogenic and antitumor activities," Biochemical Pharmacology, vol. 65, no. 2, pp. 173-179, 2003.

[48] J. Iida, K. L. Wilhelmson, J. Ng et al., "Cell surface chondroitin sulfate glycosaminoglycan in melanoma: role in the activation of pro-MMP-2 (pro-gelatinase A)," Biochemical Journal, vol. 403, no. 3, pp. 553-563, 2007.

[49] N. Isnard, L. Robert, and G. Renard, "Effect of sulfated GAGs on the expression and activation of MMP-2 and MMP-9 in corneal and dermal explant cultures," Cell Biology International, vol. 27, no. 9, pp. 779-784, 2003.

[50] S. Sandya and P. R. Sudhakaran, "Effect of glycosaminoglycans on matrix metalloproteinases in type II collagen-induced experimental arthritis," Experimental Biology and Medicine, vol. 232, no. 5, pp. 629-637, 2007.

[51] M. Borgenström, A. Wärri, K. Hiilesvuo et al., "O-sulfated bacterial polysaccharides with low anticoagulant activity inhibit metastasis," Seminars in Thrombosis and Hemostasis, vol. 33, no. 5, pp. 547-556, 2007.

[52] S. Chen, J. Wang, C. Xue et al., "Sulfation of a squid ink polysaccharide and its inhibitory effect on tumor cell metastasis," Carbohydrate Polymers, vol. 81, no. 3, pp. 560-566, 2010.

[53] S. Rodríguez-Nieto, M. González-Iriarte, R. Carmona, R. Muñoz-Chápuli, M. A. Medina, and A. R. Quesada, "Antiangiogenic activity of aeroplysinin-1, a brominated compound isolated from a marine sponge," The FASEB Journal, vol. 16, no. 2, pp. 261-263, 2002.

[54] R. G. Kerr and S. S. Kerr, "Marine natural products as therapeutic agents," Expert Opinion on Therapeutic Patents, vol. 9, no. 9, pp. 1207-1222, 1999.

[55] J. H. Jung, C. J. Sim, and C.-O. Lee, "Cytotoxic compounds from a two-sponge association," Journal of Natural Products, vol. 58, no. 11, pp. 1722-1726, 1995.

[56] J. S. Shim, H.-S. Lee, J. Shin, and H. J. Kwon, "Psammaplin $\mathrm{A}$, a marine natural product, inhibits aminopeptidase $\mathrm{N}$ and suppresses angiogenesis in vitro," Cancer Letters, vol. 203, no. 2, pp. 163-169, 2004.

[57] U. Staedt, H. Leweling, R. Gladisch, C. Kortsik, E. Hagmuller, and E. Holm, "Effects of ornithine aspartate on plasma ammonia and plasma and amino acids in patients with cirrhosis. A double-blind, randomized study using a four-fold crossover design," Journal of Hepatology, vol. 19, no. 3, pp. 424-430, 1993.

[58] H. Tokuda, Y. Oiso, and O. Kozawa, "Protein kinase C activation amplifies prostaglandin $\mathrm{F}(2 \alpha)$-induced prostaglandin E2 synthesis in osteoblast-like cells," Journal of Cellular Biochemistry, vol. 48, no. 3, pp. 262-268, 1992.

[59] B. Ryu, Z.-J. Qian, and S.-K. Kim, "Purification of a peptide from seahorse, that inhibits TPA-induced MMP, iNOS and COX- 2 expression through MAPK and NF- $\kappa$ B activation, and induces human osteoblastic and chondrocytic differentiation," Chemico-Biological Interactions, vol. 184, no. 3, pp. 413-422, 2010.
[60] C. Montagnani, F. Le Roux, F. Berthe, and J.-M. Escoubas, "Cg-TIMP, an inducible tissue inhibitor of metalloproteinase from the Pacific oyster Crassostrea gigas with a potential role in wound healing and defense mechanisms," FEBS Letters, vol. 500, no. 1-2, pp. 64-70, 2001.

[61] C.-S. Kong, J.-A. Kim, B. Ahn, H.-G. Byun, and S.-K. Kim, "Carboxymethylations of chitosan and chitin inhibit MMP expression and ROS scavenging in human fibrosarcoma cells," Process Biochemistry, vol. 45, no. 2, pp. 179-186, 2010.

[62] M.-M. Kim and S.-K. Kim, "Chitooligosaccharides inhibit activation and expression of matrix metalloproteinase-2 in human dermal fibroblasts," FEBS Letters, vol. 580, no. 11, pp. 2661-2666, 2006.

[63] N. Rajapakse, M.-M. Kim, E. Mendis, R. Huang, and S.K. Kim, "Carboxylated chitooligosaccharides (CCOS) inhibit MMP-9 expression in human fibrosarcoma cells via downregulation of AP-1," Biochimica et Biophysica Acta, vol. 1760, no. 12, pp. 1780-1788, 2006.

[64] A. S. Brito, D. S. Arimatéia, L. R. Souza et al., "Antiinflammatory properties of a heparin-like glycosaminoglycan with reduced anti-coagulant activity isolated from a marine shrimp," Bioorganic and Medicinal Chemistry, vol. 16, no. 21, pp. 9588-9595, 2008.

[65] J. L. Dreyfuss, C. V. Regatieri, M. A. Lima et al., "A heparin mimetic isolated from a marine shrimp suppresses neovascularization," Journal of Thrombosis and Haemostasis, vol. 8, no. 8, pp. 1828-1837, 2010.

[66] Y. Athukorala, G. N. Ahn, Y.-H. Jee et al., "Antiproliferative activity of sulfated polysaccharide isolated from an enzymatic digest of Ecklonia cava on the U-937 cell line," Journal of Applied Phycology, vol. 21, no. 3, pp. 307-314, 2009.

[67] J. Ye, Y. Li, K. Teruya et al., "Enzyme-digested fucoidan extracts derived from seaweed Mozuku of Cladosiphon novaecaledoniae kylin inhibit invasion and angiogenesis of tumor cells," Cytotechnology, vol. 47, no. 1-3, pp. 117-126, 2005.

[68] B. Ryu, Z.-J. Qian, M.-M. Kim, K. W. Nam, and S.-K. Kim, "Anti-photoaging activity and inhibition of matrix metalloproteinase (MMP) by marine red alga, Corallina pilulifera methanol extract," Radiation Physics and Chemistry, vol. 78, no. 2, pp. 98-105, 2009.

[69] Y. Fukuyama, M. Kodama, I. Miura et al., "Structure of an anti-plasmin inhibitor, eckol, isolated from the brown alga Ecklonia kurome Okamura and inhibitory activities of its derivatives on plasma plasmin inhibitors," Chemical and Pharmaceutical Bulletin, vol. 37, no. 2, pp. 349-353, 1989.

[70] H. S. Kang, H. Y. Chung, J. H. Jung, B. W. Son, and J. S. Choi, "A new phlorotannin from the brown alga Ecklonia stolonifera," Chemical and Pharmaceutical Bulletin, vol. 51, no. 8, pp. 1012-1014, 2003.

[71] W.-K. Jung, S.-J. Heo, Y.-J. Jeon et al., "Inhibitory effects and molecular mechanism of dieckol isolated from marine brown alga on COX-2 and iNOS in microglial cells," Journal of Agricultural and Food Chemistry, vol. 57, no. 10, pp. 44394446, 2009.

[72] C. A. Rice-Evans, N. J. Miller, and G. Paganga, "Antioxidant properties of phenolic compounds," Trends in Plant Science, vol. 2, no. 4, pp. 152-159, 1997.

[73] I. Mook-Jung, H. Kim, W. Fan et al., "Neuroprotective effects of constituents of the Oriental crude drugs, Rhodiola sacra, R. sachalinensis and Tokaku-joki-to, against betaamyloid toxicity, oxidative stress and apoptosis," Biological and Pharmaceutical Bulletin, vol. 25, no. 8, pp. 1101-1104, 2002. 
[74] Y.-X. Li, Y. Li, S.-H. Lee, Z.-J. I. Qian, and S. E.-K. Kim, "Inhibitors of oxidation and matrix metalloproteinases, floridoside, and D-Lsofloridoslde from marine red alga laurencia undulata," Journal of Agricultural and Food Chemistry, vol. 58, no. 1, pp. 578-586, 2010.

[75] M.-M. Kim, Q. V. Ta, E. Mendis et al., "Phlorotannins in Ecklonia cava extract inhibit matrix metalloproteinase activity," Life Sciences, vol. 79, no. 15, pp. 1436-1443, 2006.

[76] T. Mishima, J. Murata, M. Toyoshima et al., "Inhibition of tumor invasion and metastasis by calcium spirulan (Ca-SP), a novel sulfated polysaccharide derived from a blue-green alga, Spirulina platensis," Clinical and Experimental Metastasis, vol. 16, no. 6, pp. 541-550, 1998.

[77] L. Yang, Y. Wang, Q. Zhou et al., "Inhibitory effects of polysaccharide extract from Spirulina platensis on corneal neovascularization," Molecular Vision, vol. 15, pp. 1951-1961, 2009.

[78] H.-M. Wang, J.-L. Pan, C.-Y. Chen et al., "Identification of anti-lung cancer extract from Chlorella vulgaris C-C by antioxidant property using supercritical carbon dioxide extraction," Process Biochemistry, vol. 45, pp. 1865-1872, 2010. 

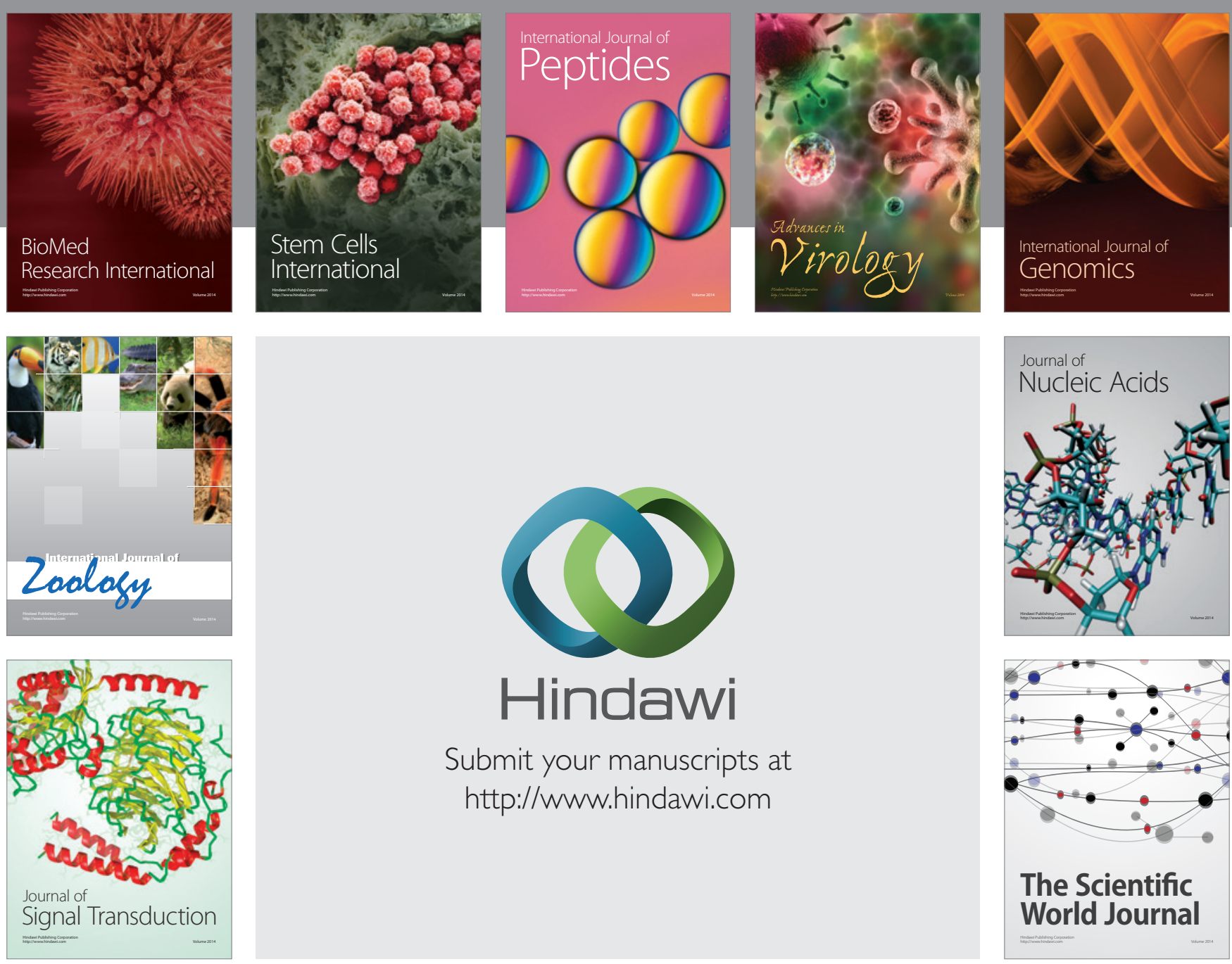

Submit your manuscripts at

http://www.hindawi.com
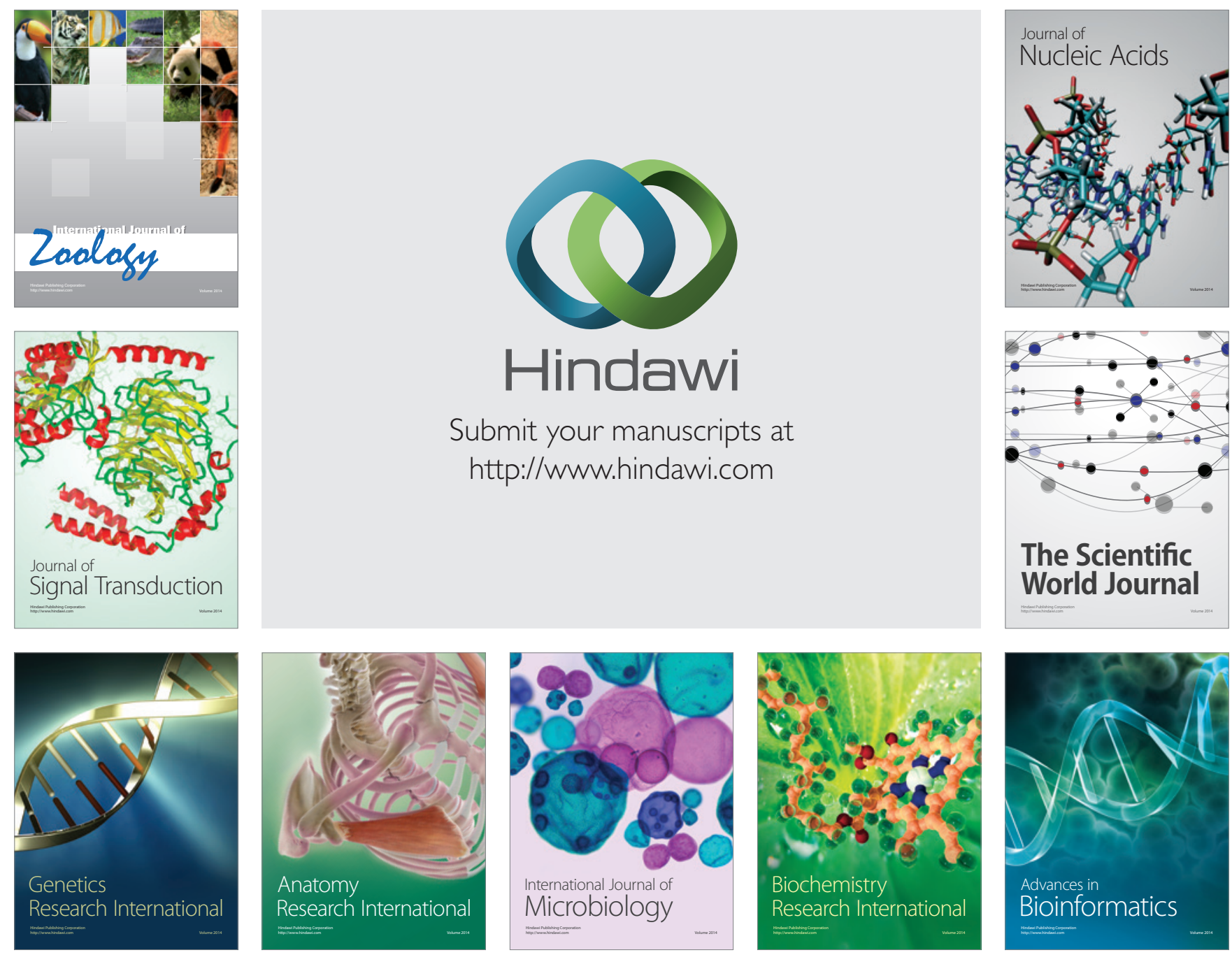

The Scientific World Journal
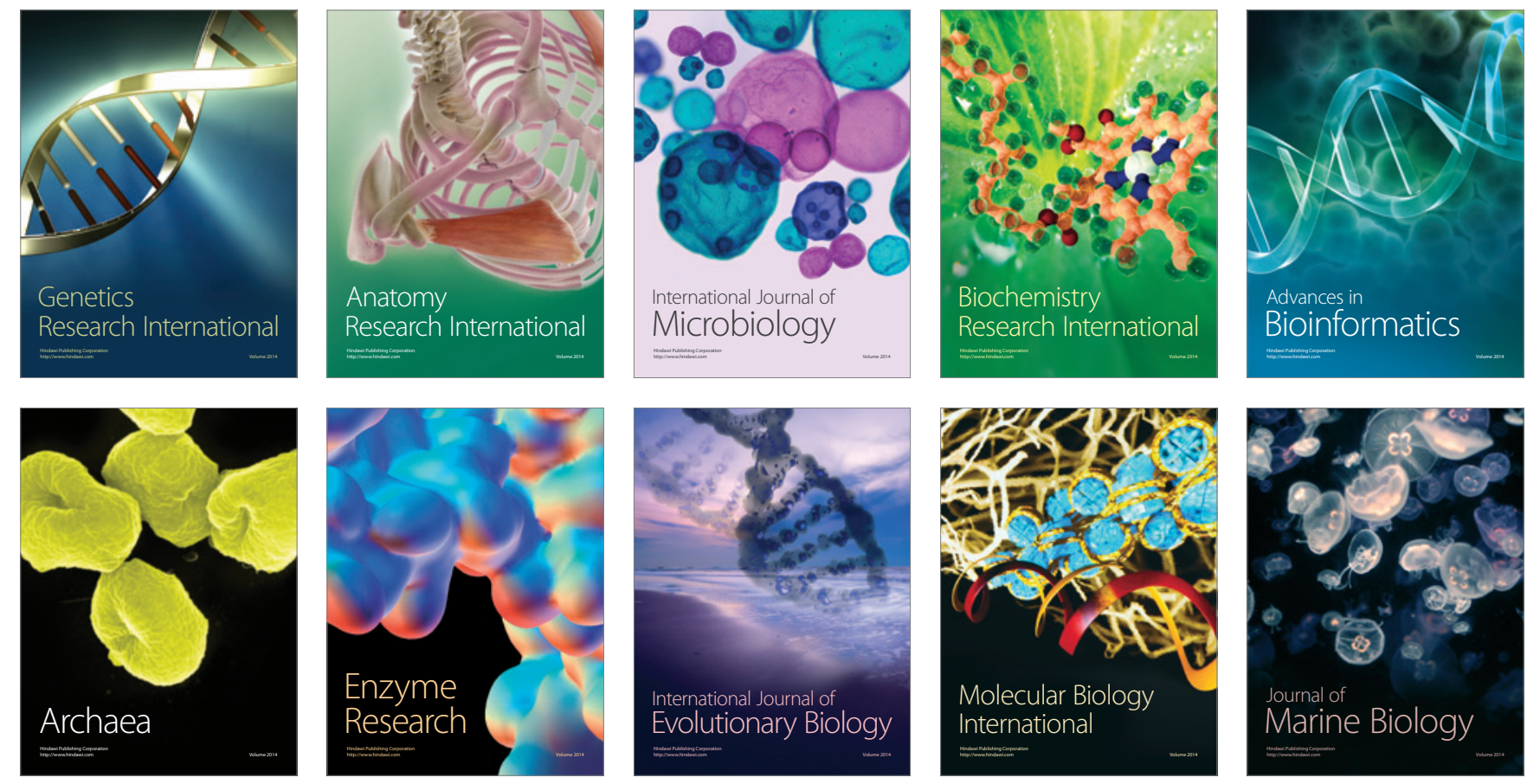